\title{
Kelola
}

\section{EVALUASI MANAJEMEN BERBASIS SEKOLAH (MBS) DI SMP NEGERI BOJA KABUPATEN KENDAL}

\author{
Rita Widjajanti \\ ritachristawijayanti@gmail.com \\ Alumni Program Pascasarjana Magister Manajemen Pendidikan \\ FKIP-Universitas Kristen Satya Wacana \\ Bambang Suteng Sulasmono \\ bambang.sulasmono@staff.uksw.edu \\ Program Pascasarjana Magister Manajemen Pendidikan \\ FKIP-Universitas Kristen Satya Wacana
}

\begin{abstract}
The study aimed to evaluate 1) whether the PAKEM plan carried out as a fulfillment of the standardized goal-oriented learning plan. 2) The performance of PAKEM learning carried out looking into whether it is in accordance with the goal-oriented plans. 3) The outputs of PAKEM learning, measured by the achievement of the learning objectives. The research conducted here has applied an evaluative approach using both quantitative and qualitative methodology. This research was conducted in SMPN 2 Boja Kendal regency. The respondents assigned to the research were principal, 20 classroom teachers of IX grade and 30 students of class IX C. The data collection techniques used observation, documentation study and interview. The quantitative data analysis was conducted to gain the results of the data of observation and of studying the documents, whereas the qualitative data analysis was carried out to examine the results of the interviews. The research showed that (1) the PAKEM learning plan carried out had fulfilled the standardized goal-oriented learning plan. Nevertheless, the teachers' competence in selecting and making use of teaching media needs improving. Teachers as individuals or with the support of school may do this either. (2) The performance of PAKEM learning carried out has been done well in accordance with the goal-oriented plan because all the teachers have achieved good grades of teaching performance. However, to enhance their teaching performance, it is necessary for the teachers to improve their competence in making use of the available learning and teaching sources, teaching media and in assessing the students learning. (3) The outputs of PAKEM learning have been able to measure the goal achievement of learning. This has been proven by the fact that a lot of students have passed most of the school subjects ( 8 subjects) achieving grades higher than the minimum grades required to pass them. Referring to the minimum grade required to pass the subjects, only a few students have not passed 4 of them. Nevertheless, school needs to gradually raise the minimum passing grade in order to be equal to the national one.
\end{abstract}

Keywords: program evaluation, school-based management, PAKEM 


\section{PENDAHULUAN}

Manajemen Berbasis Sekolah (MBS) menurut Mulyasa, (2014: 11) adalah suatu konsep yang menawarkan otonomi pada sekolah untuk menentukan kebijakan sekolah dalam rangka meningkatkan mutu, efisiensi dan pemerataan pendidikan agar dapat mengakomodasi keinginan masyarakat setempat serta menjalin kerjasama yang erat antara sekolah, masyarakat dan pemerintah Manajemen Berbasis Sekolah (MBS) atau School Based Management merupakan model penyelenggaraan pendidikan untuk mencapai mutu pendidikan yang sesuai dengan paradigma desentralisasi. Masih menurut Mulyasa (2014: 24), MBS merupakan salah satu wujud dari reformasi pendidikan yang menawarkan kepada sekolah untuk menyediakan pendidikan yang lebih baik dan memadai bagi para peserta didik. Otonomi dalam manajemen merupakan peluang bagi sekolah untuk meningkatkan kinerja staff, menawarkan partisipasi langsung kelompok-kelompok yang terkait, dan meningkatkan pemahaman masyarakat terhadap pendidikan. Terdapat 3 (tiga) pilar dalam MBS yaitu: a) Manajemen sekolah, b) Pembelajaran Aktif Kreatif dan Menyenangkan (PAKEM), dan c) Peran serta masyarakat. Ketiga pilar MBS itu -manajemen sekolah, PAKEM, dan peran serta masyarakat- perlu terus dan semakin ditingkatkan guna mewujudkan pendidikan yang bermutu baik dalam hal kualitas pembelajaran, kurikulum, pendidik, tenaga kependidikan lainnya, maupun pelayanan pendidikan secara keseluruhan.

PAKEM adalah pendekatan yang memungkinkan peserta didik mengerjakan kegiatan beragam untuk mengembangkan ketrampilan, sikap, dan pemahamannya dengan penekanan belajar sambil bekerja. Sementara, guru menggunakan berbagai sumber dan alat bantu belajar, termasuk pemanfaatan lingkungan, supaya pembelajaran lebih menarik, menyenangkan, dan efektif (Asmani, 2013: 59). PAKEM berasal dari konsep bahwa pembelajaran harus berpusat pada siswa (student centered learning) dan pembelajaran harus bersifat menyenangkan (learning is fun), agar mereka termotivasi untuk terus belajar sendiri tanpa diperintah dan agar mereka tidak merasa terbebani atau merasa takut (Rusman, 2010: 321). Lebih lanjut menurut Rusman (2010: 323), dalam model PAKEM guru dituntut untuk dapat melakukan kegiatan pembelajaran yang dapat melibatkan siswa melalui kegiatankegiatan yang partisipatif, aktif, kreatif, efektif dan menyenangkan yang pada akhirnya membuat siswa dapat menciptakan karya, gagasan, pendapat, ide atas hasil penemuannya dan usahanya sendiri, bukan dari gurunya.

SMP Negeri 2 Boja Kabupaten Kendal merupakan sekolah Standar Nasional yang sejak tahun 2010 sudah menerapkan Manajemen Berbasis Sekolah. Sekolah ini sebenarnya sangat ideal untuk menjadi sekolah yang berprestasi, baik di bidang akademik maupun non akademik. Hal ini didukung dengan kondisi antara lain: 1) lokasi sekolah yang sangat strategis dan menjadi pilihan orang tua, 2) jumlah guru yang memenuhi syarat dalam jumlah, kualifikasi maupun kompetensinya, 3) guru mengajar sesuai bidangnya, 4) jumlah tenaga kependidikan yang memenuhi syarat baik kualifikasi dan kompetensinya, 5) ruang kelas yang cukup, ruang penunjang lainnya yang memenuhi syarat (ruang ketrampilan, perpustakaan, laboratorium, ruang media, tempat ibadah), 6) serta peralatan dan media pembelajaran yang cukup. Namun ketersediaan berbagai kondisi yang ideal tersebut belum seimbang dengan mutu/prestasi yang diperoleh oleh sekolah. Hal ini dibuktikan dengan nilai 
ujian nasional yang fluktuatif dalam kurun tiga tahun terakhir, sebagaimana terlihat pada tabel berikut. dilakukan. Pengecekan ini dilakukan secara terus menerus dan berkesinambungan sehingga diketahui ketercapaian tujuan perencanaan program pembelajaran PAKEM. Pada tahap pelaksanaan, peneliti melakukan pantauan

Tabel 1 Hasil UN Siswa SMPN 2 Boja Tahun Ajaran 2011/2012 - 2013/2014

\begin{tabular}{cccccccc}
\hline No & Tahun Ajaran & $\begin{array}{c}\text { Bhs } \\
\text { Ind }\end{array}$ & $\begin{array}{c}\text { Bhs } \\
\text { Ingg }\end{array}$ & MTK & IPA & $\begin{array}{c}\text { Rata- } \\
\text { rata }\end{array}$ & $\begin{array}{c}\text { Peringkat } \\
\text { Kab }\end{array}$ \\
\hline 1 & $2011 / 2012$ & 8,39 & 5,63 & 6,37 & 7,25 & 6,91 & 19 \\
2 & $2012 / 2013$ & 7,88 & 5,57 & 6,48 & 5,92 & 6,46 & 5 \\
3 & $2013 / 2014$ & 7,50 & 5,87 & 5,10 & 5,74 & 6,05 & 15 \\
\hline
\end{tabular}

Sumber: Data diolah, 2015

Hal di atas mengisyaratkan perlunya dilakukan evaluasi terhadap program MBS khususnya dalam aspek pembelajaran PAKEM di SMPN 2 Boja. Evaluasi ini dimaksudkan untuk mengetahui berbagai kendala dan kekurangan serta kelebihan proses pembelajaran yang berlangsung di SMPN 2 Boja selama ini. Mengingat tidak bisa dipastikannya sebuah program pembelajaran yang sama akan memberikan hasil yang sama pula pada tempat dan waktu yang berbeda. Tujuan diadakannya evaluasi program adalah untuk mengetahui pencapaian tujuan program dengan langkah mengetahui keterlaksanaan kegiatan program, karena evaluator program ingin mengetahui bagian mana dari komponen dan sub komponen program yang belum terlaksana dan apa sebabnya (Arikunto, 2008: 18).

Penelitian ini menggunakan Model Goal Oriented Evaluation. Goal oriented evaluation atau evaluasi yang berorientasi pada tujuan, merupakan sebuah model evaluasi yang menekankan peninjauan pada tujuan sejak awal kegiatan dan berlangsung secara berkesinambungan. Pada tahap perencanaan dalam PAKEM di SMPN 2 Boja Kabupaten Kendal, peneliti melakukan observasi terhadap proses perencanaan pembelajaran yang telah terhadap proses pelaksanaan pembelajaran yang telah dilakukan oleh guru di kelas. Pengecekan ini dilakukan secara terus menerus dan berkesinambungan sehingga diketahui ketercapaian tujuan pelaksanaan program pembelajaran PAKEM. Pada tahap evaluasi dalam PAKEM di SMPN 2 Boja Kabupaten Kendal, peneliti secara terus menerus dan berkesinambungan melakukan pantauan terhadap evaluasi pembelajaran yang telah dilakukan oleh guru seusai pembelajaran, baik evaluasi proses maupun evaluasi hasil belajar.

Beberapa penelitian terdahulu yang memiliki relevansi dengan penelitian ini adalah sebagai berikut. Pertama, penelitian Tri Wahyuningsih (2010) dengan judul Implementasi MBS dalam Upaya Peningkatan Mutu Sekolah di SMPN 1 Purwokerto Tahun Ajaran 2010/2011. Hasil penelitian menunjukkan bahwa program implementasi MBS mampu meningkatkan mutu pendidikan di sekolah yang meliputi SDM guru serta hasil belajar siswa secara bertahap dan berkelanjutan serta adanya kerjasama antar pihak secara intensif. Kedua, penelitian Blimpo dan Evans (2011) yang berjudul School-Based Management and Educational Outcomes: Lessons from a Randomized Field Experiment. Hasil 
penelitian ini menunjukkan bahwa proses pembelajaran menjadi lebih bernilai dengan hasil optimal jika dikelola secara efektif dan efisien dengan menerapkan model manajemen berbasis sekolah. Ketiga, penelitian Arifin (2007) dengan judul Penerapan Model PAKEM Dalam Meningkatkan Mutu Pembelajaran Gaya Gesekan Pada Siswa Kelas V SD Laboratorium Universitas Negeri Gorontalo. Hasil yang diperoleh dari penelitian ini adalah model pembelajaran aktif, kreatif, efektif dan menyenangkan (PAKEM) dapat diterapkan dalam meningkatkan mutu pembelajaran gaya gesekan pada peserta didik kelas V Sekolah Dasar Laboratorium Universitas Negeri Gorontalo. Keempat, Ratam (2009) dalam penelitiannya yang berjudul Pengaruh Pola Pembelajaran Aktif, Kreatif dan Menyenangkan (PAKEM) dan Motivasi Belajar terhadap Ketuntasan IPS Materi Sejarah siswa Sekolah Dasar di Kecamatan Karanganyar Kabupaten Purbalingga, menemukan bahwa pola pembelajaran PAKEM lebih efektif dalam menolong siswa mencapai ketuntasan belajar dari pada pola konvensial. Kelima, Syaikhudin (2008) dalam penelitiannya yang berjudul Evaluasi Pelaksanaan Model Pembelajaran Aktif, Kreatif, Efektif, dan Menyenangkan (PAKEM) di Madrasah Ibtidaiyah Negeri (MIN) Jejeran Bantul Yogyakarta, menunjukkan bahwa (1) $38 \%$ guru termasuk dalam kategori baik dan $14 \%$ sangat baik dalam hal pemahaman tentang pembelajaran PAKEM (2) $48 \%$ guru termasuk kategori baik dan $9 \%$ Guru masuk dalam kategori sangat baik dalam hal pelaksanaan pembelajaran PAKEM. Kelima penelitian di atas memiliki kesamaan yaitu berupa penelitian evaluatif terhadap pembelajaran dalam konteks manajemen berbasis sekolah, yang di Indonesia disebut PAKEM. Penelitian yang hendak dilakukan berbeda dengan penelitian terdahulu, baik dari segi model evaluasi yang hendak digunakan maupun lokasi penelitiannya.

Berdasarkan uraian latar belakang di atas maka peneliti tertarik untuk mengadakan penelitian dengan judul "Evaluasi Manajemen Berbasis Sekolah (MBS) dalam PAKEM di SMP Negeri 2 Boja Kabupaten Kendal." Sejalan dengan latar belakang di atas maka rumusan masalah dalam penelitian ini adalah: 1)apakah perencanaan pembelajaran PAKEM di SMPN 2 Boja Kabupaten Kendal memenuhi standar RPP yang berorientasi pada tujuan?,2) apakah pelaksanaan pembelajaran PAKEM di SMPN 2 Boja Kabupaten Kendal sesuai dengan perencanaan yang berorientasi pada tujuan?, dan 3) apakah evaluasi pembelajaran PAKEM di SMPN 2 Boja Kabupaten Kendal dapat mengukur ketercapaian tujuan pembelajaran? Tujuan dari penelitian ini adalah untuk mengevaluasi perencanaan pembelajaran PAKEM dalam pemenuhan standar RPP yang berorientasi pada tujuan, dan pelaksanaan pembelajaran PAKEM dalam kesesuaiannya dengan perencanaan, serta evaluasi pembelajaran PAKEM yang diukur dengan ketercapaian tujuan pembelajaran.

\section{METODE PENELITIAN}

Jenis penelitian ini adalah penelitian evaluatif dengan pendekatan kuantitatif dan kualitatif. Model evaluasi yang digunakan adalah model evaluasi berbasis tujuan ( $g$ oal oriented evaluation model). Subyek dalam penelitian ini adalah kepala sekolah, 20 guru mata pelajaran yang mengajar di kelas IX SMPN 2 Boja Kabupaten Kendal. Teknik pengumpulan data yang digunakan mencakup observasi, studi dokumen dan wawancara. Analisis data menggunakan metode campuran yaitu metode kuantitatif dan kualitatif. Data kualitatif merupakan data yang dikumpulkan 
wawancara dengan kepala sekolah maupun guru. Sedang data kuantitatif berupa data angka yang diperoleh melalui penilaian perencanaan pembelajaran oleh guru dengan menggunakan instrumen IPKG 1, dan skor pelaksanaan pembelajaran yang dilakukan oleh guru dengan menggunakan instrumen IPKG 2. Kualitas perencanaan dan pelaksanaan pembelajaran guru diklasifikasikan dalam rentang skor pada Tabel 2.

\section{HASIL PENELITIAN DAN PEMBAHASAN}

\section{Hasil Penelitian}

a. Hasil Evaluasi Perencanaan Pembelajaran.

Penilaian terhadap RPP 20 guru yang mengajar di kelas IX, menghasilkan data perencanaan pembelajaran per komponennya, tergambar dalam tabel 3.

Tabel 2 Rentang skor Kualitas Perencanaan dan Pelaksanaan Pembelajaran

\begin{tabular}{ccc}
\hline Rentang skor & Nilai & Kualitas \\
\hline $86-100$ & A & Sangat Baik \\
$71-85$ & B & Baik \\
$56-70$ & C & Cukup \\
\hline$<55$ & D & Kurang \\
\hline
\end{tabular}

Tabel 3 Rekapitulasi Nilai Komponen Perencanaan Pembelajaran Guru

\begin{tabular}{|c|c|c|c|c|c|c|c|c|c|}
\hline \multirow{2}{*}{ No } & \multirow{2}{*}{$\begin{array}{l}\text { Nama } \\
\text { guru/ } \\
\text { Kode }\end{array}$} & \multirow{2}{*}{ Mata pelajaran } & \multicolumn{5}{|c|}{ Komponen Perencanaan } & \multirow{2}{*}{ Jumlah } & \multirow{2}{*}{ Rata-rata } \\
\hline & & & 1 & 2 & 3 & 4 & 5 & & \\
\hline 1 & Gr 1 & Bahasa Indonesia & 4 & 3,50 & 3 & 3,50 & 3,66 & 17,66 & 3,53 \\
\hline 2 & Gr 2 & PKn & 4 & 3 & 2,66 & 3,25 & 2,66 & 15,57 & 3,11 \\
\hline 3 & Gr 3 & IPA Terpadu & 4 & 3,25 & 3 & 2,55 & 3 & 15,75 & 3,15 \\
\hline 4 & Gr 4 & PAI & 4 & 3,25 & 3 & 3 & 3 & 16,25 & 3,25 \\
\hline 5 & Gr 5 & TIK & 4 & 3 & 3 & 4 & 3 & 17 & 3,43 \\
\hline 6 & Gr 6 & IPS Terpadu & 3,33 & 3 & 2,33 & 3 & 2,66 & 14,29 & 2.85 \\
\hline 7 & Gr 7 & Ketrampilan & 4 & 3 & 3 & 2 & 3 & 15,00 & 3,00 \\
\hline 8 & Gr 8 & Seni Budaya & 3,66 & 3 & 3 & 3 & 3,66 & 15,99 & 3,98 \\
\hline 9 & Gr 9 & Matematika & 4 & 3,5 & 3,25 & 3 & 2,66 & 16,41 & 3,28 \\
\hline 10 & Gr 10 & Bahasa Jawa & 3.66 & 3 & 2,66 & 2,5 & 3 & 14,82 & 2,96 \\
\hline 11 & Gr 11 & IPS Terpadu & 4 & 3 & 3 & 3 & 2,66 & 15,66 & 3,13 \\
\hline 12 & Gr 12 & IPA Terpadu & 3.66 & 3,75 & 2,66 & 3 & 3 & 16.07 & 3,21 \\
\hline 13 & Gr 13 & BK & 3,25 & 3 & 3,66 & 3,5 & 4 & 17,41 & 3,48 \\
\hline 14 & Gr 14 & Penjasorkes & 4 & 3,25 & 3 & 3,25 & 3,66 & 17.16 & 3,43 \\
\hline 15 & Gr 15 & Bahasa Inggris & 3 & 3 & 2,33 & 3 & 3 & 14,33 & 2,86 \\
\hline 16 & Gr 16 & Bahasa Inggris & 3,66 & 3 & 2,33 & 3 & 3 & 14,99 & 2,99 \\
\hline 17 & Gr 17 & Bahasa Inggris & 3,33 & 3,75 & 2,66 & 3,25 & 3 & 15,99 & 3,19 \\
\hline 18 & Gr 18 & Matematika & 4 & 3,75 & 3 & 3,25 & 3 & 17 & 3,4 \\
\hline 19 & Gr 19 & Matematika & 3.33 & 3,50 & 2,66 & 3 & 3 & 15,41 & 3,08 \\
\hline \multirow[t]{3}{*}{20} & Gr 20 & Matematika & 4 & 3,25 & 3 & 3 & 3 & 16,25 & 3,15 \\
\hline & Jumlah & & 71,63 & 64,7 & 57,2 & 61,0 & 61,2 & 315,92 & 63,18 \\
\hline & $\begin{array}{l}\text { Nilai Kon } \\
=\text { Nilai di }\end{array}$ & $\begin{array}{l}\text { en (skala ratusan) } \\
\text { eh : Nilai } \\
\text { maksimal x } 100\end{array}$ & 89,53 & 80,98 & 71,5 & 76,31 & 76,61 & 394,9 & 78,98 \\
\hline
\end{tabular}

Keterangan: Lima Komponen perencanaan pembelajaran meliputi: 1) Perumusan Tujuan Pembelajar-an, 2) Pemilihan dan pengorganisasian Materi Pembelajaran, 3) Pemilihan Sumber Belajar/Media Pembelajaran, 4) Metode Pembelajaran, dan 5) Penilaian hasil Belajar. 
Menurut Tabel 3, nilai tertinggi yang diperoleh para Guru adalah komponen ke-1 yaitu perumusan tujuan pembelajaran dengan nilai rata-rata 89,53 , nilai terendah adalah komponen ke-3 yaitu pemilihan sumber belajar/ media pembelajaran dengan nilai rata-rata 71,5. Rendahnya nilai ini disebabkan antara lain oleh keterbatasan sumber belajar/media pembelajaran yang dimiliki sekolah, dan keterbatasan kemampuan guru dalam menggunakan media pembelajaran yang ada di sekolah. Tampak juga bahwa nilai rata-rata setiap komponen perencanaan belum mencapai kategori Amat Baik. Penyebabnya antara lain adalah karena sebagian guru masih meng-copy paste RPP yang di buat oleh MGMP atau sumber lain yang belum disesuaikan dengan kondisi sekolah. b. Evaluasi Pelaksanaan Pembelajaran

Hasil observasi terhadap pelaksanaan pembelajaran dari 20 guru mata pelajaran yang mengajar kelas IX, disajikan dalam Tabel 4.

Menurut Tabel 4, nilai tertinggi yang dicapai oleh para Guru adalah nilai dalam komponen ke- 6 yaitu penggunaan bahasa dengan tara-rata nilai 92,02 (A), sedang nilai terendah adalah komponen ke-4 yaitu pemilihan sumber belajar/media pembelajaran dengan nilai rata-rata 69,81 (C). Nilai terendah kedua adalah nilai komponen ke-7 yaitu penilaian proses dan hasil belajar dengan nilai rata-rata 70,41. Rendahnya nilai komponen ke4 yaitu pemanfaatan sumber belajar/media pembelajaran disebabkan antara lain keterbatasan sarana dan prasarana khususnya

Tabel 4. Rekapitulasi Nilai Komponen Pelaksanaan Pembelajaran Guru

\begin{tabular}{|c|c|c|c|c|c|c|c|c|c|c|c|c|}
\hline \multirow{2}{*}{ No } & \multirow{2}{*}{$\begin{array}{l}\text { Nama } \\
\text { guru/ } \\
\text { Kode } \\
\end{array}$} & \multirow{2}{*}{$\begin{array}{c}\text { Mata } \\
\text { pelajaran }\end{array}$} & \multicolumn{8}{|c|}{ Komponen Pelaksanaan Pembelajaran } & \multirow{2}{*}{$\begin{array}{l}\text { Jum } \\
\text { lah }\end{array}$} & \multirow{2}{*}{$\begin{array}{l}\text { Rata- } \\
\text { rata }\end{array}$} \\
\hline & & & 1 & 2 & 3 & 4 & 5 & 6 & 7 & 8 & & \\
\hline 1 & Gr 1 & Bhs.Ind & 4 & 3,5 & 3,11 & 2,66 & 3,5 & 3,66 & 3 & 3,25 & 26,93 & 3,36 \\
\hline 2 & Gr 2 & PKn & 3,5 & 3,25 & 3,28 & 2,33 & 3,16 & 4 & 3 & 3,25 & 25,77 & 3,22 \\
\hline 3 & Gr 3 & IPA & 4 & 3,66 & 3,33 & 3 & 2,66 & 3,16 & 2,5 & 3,25 & 25,56 & 3,19 \\
\hline 4 & Gr 4 & PAI & 3,25 & 3 & 3 & 2,66 & 3 & 3,66 & 2,5 & 3,25 & 24,32 & 3,04 \\
\hline 5 & Gr 5 & TIK & 3,25 & 3 & 3 & 2,66 & 2,83 & 4 & 3 & 3,25 & 24,99 & 3,12 \\
\hline 6 & Gr 6 & IPS & 3,25 & 3 & 3,14 & 2,66 & 3 & 3,66 & 3 & 3 & 24,71 & 3,08 \\
\hline 7 & Gr 7 & Ketrampila & 3,5 & 3 & 2,77 & 3 & 3,16 & 4 & 2,5 & 3,25 & 25,18 & 3,14 \\
\hline 8 & Gr 8 & S. Budaya & 3,25 & 3,4 & 3,14 & 3,33 & 3 & 4 & 3 & 3,25 & 26,37 & 3.29 \\
\hline 9 & Gr 9 & Mat & 3,5 & 3 & 3,16 & 3,16 & 3 & 2,66 & 2,83 & 3,25 & 24,56 & 3,07 \\
\hline 10 & Gr 10 & Bhs. Jawa & 3,5 & 3 & 2,77 & 3 & 3,16 & 4 & 2,5 & 3,25 & 25,18 & 3,14 \\
\hline 11 & Gr 11 & IPS & 4 & 3 & 3,14 & 2,66 & 3 & 4 & 3 & 3,25 & 26,05 & 3,25 \\
\hline 12 & Gr 12 & IPA & 3,5 & 3,66 & 3,28 & 2 & 2,83 & 4 & 3 & 3,25 & 25,52 & 3,19 \\
\hline 13 & Gr 13 & B K & 3,5 & 3 & 2,77 & 3 & 3,16 & 4 & 2,5 & 3,25 & 25,18 & 3,14 \\
\hline 14 & Gr 14 & Penjas & 3,5 & 3 & 2,77 & 3 & 3,16 & 4 & 2,5 & 3,25 & 25,18 & 3,14 \\
\hline 15 & Gr 15 & B. Inggris & 3,25 & 3,4 & 3,14 & 3,33 & 3 & 4 & 3 & 3,25 & 26,37 & 3,29 \\
\hline 16 & Gr 16 & B. Inggris & 3,5 & 3 & 2,77 & 2,66 & 2,83 & 4 & 3 & 3 & 24,76 & 3,09 \\
\hline 17 & Gr 17 & B. Inggris & 4 & 3,66 & 3,14 & 2,66 & 3,16 & 3,66 & 3 & 3,25 & 26,53 & 3,31 \\
\hline 18 & Gr 18 & Math & 3,5 & 3,33 & 3,16 & 3 & 3 & 3,16 & 3 & 2,75 & 24,9 & 3,11 \\
\hline 19 & Gr 19 & Math & 3,5 & 3 & 3,16 & 2,75 & 2,33 & 3 & 3 & 3,25 & 23,99 & 2.99 \\
\hline 20 & Gr 20 & Math & 3.5 & 3 & 3.16 & 2.33 & 2.88 & 3 & 2.5 & 3 & 23.37 & 2.92 \\
\hline \multicolumn{3}{|c|}{ Jumlah } & 71 & 63.86 & 61.19 & 55.85 & 59.82 & 73.62 & 56.33 & 63.75 & 505.4 & 63.17 \\
\hline \multicolumn{3}{|c|}{$\begin{array}{l}\text { Nilai Komponen } \\
\text { (skala ratusan) } \\
=\text { Nilai diperoleh : } \\
\text { Nilai maksimal x } 100\end{array}$} & 88.75 & 79.82 & 76.49 & 69.81 & 74.77 & 92.02 & 70.41 & 79.68 & 631.78 & 78.97 \\
\hline
\end{tabular}

Sumber: Data penelitian, diolah

Keterangan : komponen I adalah membuka pelajaran, komponen 2 adalah penguasaan materi, komponen 3 adalah pendekatan dan strategi, komponen 4 adalah pemanfaatan sumber belajar/media pembelajaran, komponen 5 adalah peran aktif siswa, komponen 6 adalah penggunaan bahasa, komponen 7 adalah penilaian proses dan hasil belajar, serta komponen 8 adalah menutup pelajaran. 
sumber belajar/media pembelajaran yang dimiliki sekolah, dan masih rendahnya kemampuan guru dalam menggunakan media pembelajaran yang ada. Sedang rendahnya nilai komponen ke-7 yaitu penilaian proses dan hasil belajar siswa disebabkan antara lain : guru tidak/ belum melaksanakan penilaian proses dan hasil belajar sesuai rencana karena sebagian guru masih ada yang berpendapat bahwa yang terpenting sudah menyusun perencanaan, dan pelaksanaan nnya bolehtidak sesuai dengan yang direncanakan.

\section{c. Evaluasi terhadap penilaian hasil belajar}

Data hasil evaluasi terhadap, penilaian hasil belajar siswa yang dilakukan oleh para guru setelah melaksanakan pembelajaran tergambar dalam Tabel 5. Berdasarkan tabel di bawah ini, tampak bahwa jika dibandingkan dengan Kriteria Ketuntasan Minimal (KKM) untuk tiap-tiap matapelajaran yang sudah ditetapkan oleh sekolah, maka dari 12 mata pelajaran yang diajarkan, terdapat 8 mata pelajaran yang seluruh siswanya telah mencapai nilai KKM. Sedangkan 4 mata pelajaran yang lain yaitu PKn, Bahasa Inggris, Matematika, IPS, terdapat sejumlah siswa yang belum mencapai KKM. Sepintas tampak bahwa berdasarkan data di atas secara umum kualitas hasil belajar siswa pada ulangan harian yang diselenggarakan oleh para Guru sudah termasuk baik. Namun jika ditilik lebih dalam akan tampak bahwa dari dua belas mata pelajaran yang ada, hanya dua mata pelajaran yang disajikan hanya ada 2 (dua) matapelajaran yaitu IPS dan Mulok Ketrampilan yang KKM nya

Tabel 5 Rekap Nilai Ulangan Harian Kedua Kelas IX C

\begin{tabular}{|c|c|c|c|c|c|c|c|c|c|c|c|c|c|c|c|}
\hline \multicolumn{2}{|c|}{ Nomor } & \multicolumn{12}{|c|}{ Nilai per Mata Pelajaran } & \multirow[b]{2}{*}{ 吾 } & \multirow[b]{2}{*}{ 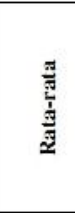 } \\
\hline$\underline{E}$ & 兰 & 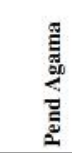 & 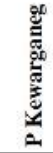 & 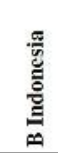 & 总 & 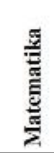 & 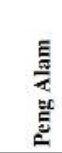 & 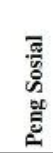 & 焉 & 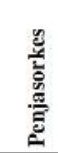 & 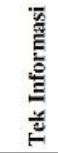 & 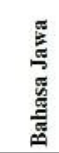 & $\begin{array}{l}\frac{\Xi}{2} \\
\frac{y}{5} \\
\frac{E}{2}\end{array}$ & & \\
\hline \multicolumn{2}{|c|}{ KKM } & 73 & 73 & 73 & 70 & 70 & 70 & 75 & 72 & 72 & 72 & 72 & 75 & & \\
\hline 1 & 5984 & 73 & 84 & 80 & 75 & 70 & 80 & 75 & 80 & 75 & 75 & 75 & 80 & 922 & 76,83 \\
\hline 2 & 6015 & 75 & 72 & 73 & 70 & 80 & 80 & 75 & 80 & 80 & 75 & 75 & 80 & 915 & 76,25 \\
\hline 3 & 5951 & 80 & 80 & 84 & 70 & 75 & 85 & 85 & 85 & 80 & 80 & 80 & 80 & 964 & 80,33 \\
\hline 4 & 5922 & 75 & 72 & 80 & 70 & 75 & 85 & 85 & 85 & 80 & 85 & 80 & 85 & 957 & 79,75 \\
\hline 5 & $6(1) 83$ & 80 & 84 & 76 & 80 & 75 & 75 & 80 & 85 & 80 & 72 & 80 & 85 & 952 & 79,33 \\
\hline 6 & 6050 & 80 & 78 & 84 & 85 & 80 & 90 & 85 & 80 & 85 & 75 & 75 & 80 & 977 & 81,42 \\
\hline 7 & 5985 & 73 & 88 & 92 & 75 & 75 & 90 & 85 & 80 & 75 & 75 & 75 & 85 & 968 & 80,67 \\
\hline 8 & 6090 & 75 & 88 & 88 & 80 & 75 & 70 & 65 & 85 & 75 & 80 & 80 & 80 & 941 & 78,42 \\
\hline 9 & 5960 & 75 & 84 & 92 & 80 & 85 & 85 & 75 & 80 & 75 & 85 & 75 & 80 & 971 & 80,92 \\
\hline 10 & 5990 & 80 & 92 & 84 & 75 & 70 & 70 & 75 & 90 & 80 & 75 & 85 & 80 & 956 & 79,67 \\
\hline 11 & 6058 & 80 & 76 & 86 & 75 & 65 & 75 & 75 & 85 & 75 & 75 & 90 & 80 & 937 & 78,08 \\
\hline 12 & $6(1) 29$ & 73 & 84 & 88 & 70 & 65 & 85 & 70 & 85 & 75 & 75 & 75 & 75 & 920 & 76,67 \\
\hline 13 & 6122 & 75 & 88 & 84 & 70 & 80 & 70 & 70 & 80 & 80 & 85 & 85 & 85 & 952 & 79,33 \\
\hline 14 & $6(130)$ & 80 & 84 & 84 & 70 & 75 & 75 & 75 & 80 & 80 & 90 & 75 & 85 & 953 & 79,42 \\
\hline 15 & 5935 & 75 & 72 & 80 & 70 & 70 & 70 & 80 & 80 & 85 & 85 & 85 & 80 & 932 & 77,67 \\
\hline 16 & 6035 & 75 & 88 & 88 & 75 & 80 & 80 & 80 & 85 & 85 & 85 & 85 & 80 & 986 & 82,17 \\
\hline 17 & 5971 & 75 & 84 & 84 & 85 & 70 & 90 & 80 & 90 & 85 & 75 & 85 & 80 & 983 & 81,92 \\
\hline 18 & 6127 & 75 & 80 & 84 & 75 & 85 & 80 & 90 & 85 & 75 & 75 & 85 & 85 & 974 & 81,17 \\
\hline 19 & 6069 & 80 & 88 & 88 & 70 & 80 & 80 & 85 & 85 & 75 & 75 & 75 & 80 & 961 & 80,08 \\
\hline 20 & 5940 & 75 & 80 & 84 & 70 & 75 & 80 & 75 & 80 & 75 & 80 & 75 & 75 & 924 & 77,00 \\
\hline 21 & $60(1) 2$ & 75 & 80 & 75 & 65 & 75 & 70 & 70 & 80 & 80 & 75 & 75 & 75 & 895 & 74,58 \\
\hline 22 & $6(0) 3$ & 73 & 80 & 84 & 80 & 75 & 80 & 75 & 80 & 80 & 75 & 80 & 75 & 937 & 78,08 \\
\hline 23 & 6004 & 80 & 80 & 84 & 85 & 75 & 75 & 75 & 80 & 80 & 75 & 80 & 80 & 949 & 79,08 \\
\hline 24 & 6102 & 80 & 84 & 84 & 70 & 80 & 75 & 75 & 80 & 85 & 72 & 75 & 80 & 940 & 78,33 \\
\hline 25 & 5943 & 73 & $60)$ & 84 & 70 & 75 & 75 & 80 & 80 & 85 & 75 & 75 & 75 & 907 & 75,58 \\
\hline 26 & 6106 & 75 & 88 & 88 & 85 & 75 & 75 & 85 & 85 & 75 & 72 & 80 & 85 & 968 & 80,67 \\
\hline 27 & 6109 & 80 & 92 & 84 & 90 & 80 & 90 & 75 & 90 & 75 & 90 & 90 & 80 & 1016 & 84,67 \\
\hline 28 & 5978 & 80 & 80 & 84 & 75 & 85 & 80 & 75 & 80 & 75 & 75 & 80 & 80 & 949 & 79,08 \\
\hline 29 & 6014 & 80 & 76 & 80 & 75 & 85 & 85 & 75 & 85 & 75 & 72 & 80 & 80 & 948 & 79,00 \\
\hline 30 & 5950 & 73 & 73 & 75 & 70 & 75 & 75 & 70 & 80 & 80 & 72 & 75 & 75 & 893 & 74,42 \\
\hline \multicolumn{2}{|c|}{ Nilai Rata-rata } & 77 & 81 & 84 & 75 & 76 & 79 & 77 & 83 & 79 & 78 & 80 & 80 & 948 & 79 \\
\hline \multirow{2}{*}{\multicolumn{2}{|c|}{$\begin{array}{l}\text { Nilai Tcrtinggi } \\
\text { Nilai Terendah }\end{array}$}} & 80 & 92 & 92 & 90 & 85 & 90 & 90 & 90 & 85 & 90 & 90 & 85 & 1016 & 85 \\
\hline & & 73 & 60 & 73 & 65 & 65 & 70 & 65 & 80 & 75 & 72 & 75 & 75 & 893 & 74 \\
\hline \multirow{2}{*}{\multicolumn{2}{|c|}{ Tuntas (\%) }} & 100 & 87 & 100 & 97 & 93 & 100 & 83 & 100 & 100 & 100 & 100 & 100 & & \\
\hline & & 0 & 13 & 0 & 3 & 7 & 0 & 17 & 0 & 0 & 0 & 0 & 0 & & \\
\hline
\end{tabular}

Sumber: Data penelitian, diolah 
sama dengan KKM Nasional yaitu sebesar 75 . Selebihnya KKM 10 (sepuluh) mata pelajaran yang lain masih kurang dari 75 . Hal ini menunjukkan bahwa kualitas KKM di SMP 2 Boja mayoritas masih di bawah KKM Nasional yaitu 75. Sehingga capaian atas KKM oleh para siswa di atas, sebagian besar belum mencapai KKM Nasional.

\section{Pembahasan}

a. Pembahasan Hasil Perencanaan Pembelajaran Berdasarkan hasil penilaian perencanaan pembelajaran yang telah dipaparkan di atas, bisa dikatakan bahwa perencanaan pembelajaran yang dilakukan oleh guru-guru SMP Negeri 2 Boja pada dasarnya telah mengacu model RPP pembelajaran PAKEM yang mencakup komponen RPP yang benar yaitu meliputi: Identitas sekolah, Standar Kompetensi, Kompetensi Dasar, Indikator pencapaian hasil belajar, tujuan pembelajaran, materi pembelajaran, pendekatan dan metode pembelajaran, langkah kegiatan pembelajaran (pendahuluan, inti dan penutup), alat dan sumber belajar serta penilaian pembelajaran. Hal ini telah sesuai dengan komponen RPP PAKEM yang dikemukakan oleh Usman (2008) yang menyebutkan secara teknis rencana pembelajaran minimal mencakup komponen-komponen berikut: (1) Standar kompetensi, kompetensi dasar, dan indikator pencapaian hasil belajar, (2) Tujuan pembelajaran. (3) Materi pembelajaran. (4) Pendekatan dan metode pembelajaran. (5) Langkah-langkah kegiatan pembelajaran. (6) Alat dan sumber belajar. (7) Evaluasi pembelajaran.

Secara kualitas nilai semua komponen perencanaan pembelajaran menunjukkan nilai yang belum mencapai Amat Baik. Masih ada komponen yang sangat penting dalam sebuah perencanaan, yang nilainya masih rendah yaitu pada komponen 3 (tiga) tentang pemilihan sumberbelajar/media pembelajaran. Rendahnya kemampuan guru dalam memilih dan menggunakan sumber pembelajaran/media pembelajaran disebabkan karena sebagian guru belum memiliki kompetensi yang baik dalam memilih dan menggunakan sumber pembelajaran/media pembelajaran. Selain itu juga dikarenakan masih terbatasnya sarana prasarana/ media pembelajaran yang ada di sekolah. Hal ini perlu pendapatkan perhatian baik dari guru maupun kepala sekolah, agar guru meningkatkan kompetensinya dalam pemilihan dan pemanfaatan sumber/media pembelajaran.

Kategori nilai Baik yang diperoleh dalam perencanaan pembelajaran yang disusun oleh guru disebabkan karena sebagian besar guru aktif dalam kegiatan Musyawarah Guru Mata Pelajaran (MGMP) sekolah yang diadakan setiap 2 (dua) minggu sekali maupun MGMP Kabupaten yang diadakan setiap bulan sekali pada minggu keempat. Selain itu, kemampuan guru dalam menyusun RPP juga dipengaruhi dengan adanya fungsi kepala sekolah sebagai supervisor yang telah menjalankan tugasnya dengan baik yaitu dengan memeriksa RPP guru sebelum digunakan dalam pembelajaran. Kualitas kemampuan guru dalam menyusun RPP juga dipicu oleh adanya kegiatan rutin kompetisi guru berprestasi tingkat kabupaten yang biasa diadakan tiap semester.

b. Pembahasan Hasil Pelaksanaan Pembelajaran

Pelaksanaan pembelajaran yang dilakukan oleh guru-guru di SMP Negeri 2 Boja pada dasarnya sudah sesuai dengan model PAKEM, hal ini ditunjukkan dalam pelaksanaan pembelajarannya sudah memenuhi kriteria aktif, kreatif, efektif dan menyenangkan, namun demikian kompetensi guru tetap masih sangat perlu ditingkatkan terus agar kualitas pem- 
belajaran semakin baik sehingga hasilnya pun juga akan semakin baik. Masih dijumpai beberapa guru dalam membuka pelajaran banyak menghabiskan waktu sehingga tidak sesuai dengan yang direncanakannya.

Pada kegiatan inti, masih ada komponen yang memperoleh nilai rendah yaitu pada komponen pemanfaatan sumber belajar/media pembelajaran dan komponen penilaian proses dan hasil belajar. Hal ini terjadi karena kompetensi guru dalam pemanfaatan sumber belajar/media pembelajaran masih sangat kurang. Banyak guru yang belum mampu menggunakan komputer/LCD sebagai media. Untuk menyikapi hal tersebut, dalam kegiatan inti ini guru dituntut untuk lebih kreatif memanfaatkan lingkungan yang ada sebagai media pembelajaran. Kegiatan pembelajaran tidak harus di dalam kelas tetapi bisa juga dilakukan di luar kelas dengan memanfaatkan lingkungan yang ada. Hal ini perlu mendapatkan perhatian yang serius dari guru maupun sekolah agar kompetensi dan kreativitas guru lebih ditingkatkan, agar siswa gembira dalam mengikuti pelajaran sehingga mereka akan mencintai ilmu yang dipelajarinya. Dengan suasana yang gembira dan mencintai ilmu yang dipelajarinya tentu siswa akan lebih mudah menyerap materi pelajaran sehingga tujuan yang direncanakan bisa tercapai. Demikian halnya dengan kegiatan penutup, terkadang guru lupa tidak memberikan refleksi dan penugasan. Kegiatan refleksi sangat penting untuk mengetahui seberapa besar materi yang sudah diserap dan dipahami oleh siswa, oleh karena itu guru harus lebih disiplin dalam pemanfaatan waktu, agar semua kegiatan bisa dilaksanakan dengan baik.

Berdasarkan hasil penilaian pelaksanaan pembelajaran di atas, ternyata faktor kedisiplinan guru dalam menggunakan waktu berdasarkan perencanaan yang telah disusun perlu mendapatkan perhatian yang serius.
Secara keseluruhan nilai rata-rata pelaksanaan pembelajaran semua guru di SMP Negeri 2 Boja sudah Baik. Hal ini juga disebabkan karena adanya program kegiatan supervisi yang dilakukan oleh kepala sekolah secara rutin tiap 2 kali dalam 1 semester. Selain supervisioleh kepala sekolah, guru juga mampu menciptakan interaksi dengan siswa yang baik sehingga pembelajaran lebih kondusif. Sedangkan pada kegiatan inti pelajaran, ada dua komponen yang nilainya masih dalam kategori Cukup, yaitu komponen 4 (empat) yaitu pemanfaatan sumber belajar dan media pembelajaran dan komponen 7 (tujuh) yaitu penilaian proses dan hasil belajar. Mengingat pentingnya kedua komponen tersebut, maka guru maupun kepala sekolah agar memberikan perhatian. Rendahnya nilai kedua komponen ini disebabkan masih terbatasnya kemampuan guru dalam memanfaatkan sumber belajar dan media pembelajaran, juga disebabkan masih terbatasnya media/alat pembelajaran yang disediakan oleh sekolah.

Pada dasarnya pelaksanaan pembelajaran PAKEM di SMP 2 Boja sudah berjalan dengan baik sesuai dengan hasil penelitiannya Blimpo dan Evans (2001) yang mengatakan bahwa proses pembelajaran menjadi lebih bernilai dengan hasil optimal jika dikelola secara efektif dan efisien dengan menerapkan model PAKEM, namun masih perlu pembenahan dan peningkatan.

Disisi lain sebagai pembanding, menurut hasil penelitian yang dilakukan oleh Kafit (2009) tentang Efektifitas Penggunaan Media Pembelajaran Komputer Untuk Meningkatkan hasil Belajar Mata Pelajaran IPA Kelas VIII MTs NU Hasyim Asyari Honggowongso Jekulo Kudus, menyatakan bahwa: Penggunaan media pembelajaran komputer mampu meningkatkan prestasi belajar IPA, karena dengan menggunakan media tersebut siswa lebih ter- 
tarik dan lebih termotivasi. Dengan demikian kompetensi guru SMP Negeri 2 Boja khususnya dalam pemanfaatan sumber belajar/ media pembelajaran sangat perlu ditingkatkan agar kualitas pembelajaran semakin baik dan hasil/prestasi belajar siswa pun juga semakin meningkat.

Dengan demikian, sekalipun di SMP Negeri 2 Boja sudah mengimplementasikan MBS dan PAKEM, namun, dengan pencapaian prestasi belajar siswa yang belum memenuhi harapan, maka kompetensi guru dalam menerapkan PAKEM masih sangat perlu ditingkatkan, dan sekolah perlu memberikan dukungan dengan memberikan fasilitas yang cukup bagi guru untuk melaksanakan PAKEM.

c. Pembahasan Hasil Evaluasi Pembelajaran

Menurut Asmani (2013: 105) salah satu kriteria penilaian yang sesuai dengan konsep PAKEM yaitu penilaian yang sesuai dengan pembelajaran model PAKEM yaitu penilaian otentik yang merupakan proses pengumpulan informasi oleh guru tentang perkembangan dan pencapaian pembelajaran peserta didik melalui berbagai teknik yang mampu mengungkapkan, membuktikan atau menunjukkan secara tepat bahwa tujuan pembelajaran telah benar-benar dikuasai dan dicapai. Bentuk penilaian tes dapat dilakukan secara lisan, tertulis, dan perbuatan. Sementara itu, bentuk penilaian non-tes dilakukan dengan menggunakan skala sikap, ceklis, kuesioner, studi kasus, dan portofolio.

Mengacu pada hasil observasi pelaksanaan pembelajaran yang salah satu komponennya adalah penilaian proses dan hasil pembelajaran, ternyata yang dilaksanakan oleh guru SMP Negeri 2 Boja belum dilaksanakan dengan baik. Hal ini tentunya belum sesuai sepenuhnya dengan karateristik evaluasi yang seharusnya dilakukan dalam model PAKEM yang meliputi pretest, penilaian proses dan postest maupun bentuk penilaian lainya seperti portofolio, penugasan terstruktur maupun kegiatan mandiri terstruktur. Perencanaan evaluasi pembelajaran yang telah dilaksanakan yang meliputi kualitas butir soal, kualitas hasil belajar, kualitas waktu dalam perencanaan dan Kriteria Ketuntasan Minimal (KKM) diperoleh hasil bahwa kualitas butir soal ternyata belum semua guru menyusun instrumen penilaian secara lengkap dalam RPP.

Kualitas hasil belajar siswa SMP N 2 Boja, secara umum sebenarnya sudah baik, hal ini dibuktikan dengan 8 mata pelajaran menunjukkan semua anak telah mencapai KKM, sedangkan 4 mata pelajaran yang lain yaitu mata pelajaran PKn, Bahasa Inggris, Matematika dan IPS hanya menunjukkan beberapa anak yang belum mencapai batas tuntas. Kualitas KKM di SMP 2 Boja perlu adanya peningkatan menuju KKM Nasional yaitu 75, hal ini terlihat dari dari data KKM sekolah hanya dua mata pelajaran yang KKM nya 75 , yaitu mata pelajaran IPS dan Ketrampilan, sedangkan mata pelajaran yang lain KKM nya masih di bawah 75.

Pentingnya mengevaluasi pembelajaran karena guru akan mengetahui tingkat keberhasilan maupun bagian-bagian yang perlu diperbaiki. Hal ini sebagaimana dikemukakan oleh Uno (2008: 95), bahwa Evaluasi akhir atau post test berfungsi untuk memperoleh gambaran tentang kemampuan yang dicapai siswa pada akhir pengajaran. Jika hasil evaluasi akhir kita bandingkan dengan evaluasi awal, maka dapat diketahui seberapa jauh efek atau pengaruh dari pengajaran yang telah kita berikan, disamping sekaligus dapat pula diketahui bagian-bagian mana dari bahan pengajaran yang masih belum dipahami oleh sebagian besar siswa. 


\section{SIMPULAN DAN SARAN}

\section{Simpulan}

1. Perencanaan pembelajaran PAKEM di SMPN2 Boja Kabupaten Kendal telah memenuhi standar RPP yang berorientasi pada tujuan, akan tetapi masih perlu perbaikan dan peningkatan kompetensi guru pada komponen pemilihan dan pemanfaatan sumber/media pembelajaran, baik oleh guru secara mandiri maupun oleh sekolah

2. Pelaksanaan pembelajaran PAKEM di SMPN 2 Boja Kabupaten Kendal telah sesuai dengan perencanaan yang berorientasi pada tujuan, karena semua guru memiliki nilai pelaksanaan pembelajaran rata-rata Baik, akan tetapi agar kualitas pembelajaran menjadi lebih baik, maka guru perlu meningkatkan kompetensinya dalam komponen pemanfaatan sumber belajar/ media pembelajaran dan penilaian proses dan hasil belajar

3. Evaluasi pembelajaran PAKEM di SMPN 2 Boja Kabupaten Kendal telah dapat mengukur ketercapaian tujuan pembelajaran. Meskipun belum semua guru mata pelajaran melaksanakan penilaian sesuai dengan standar PAKEM yaitu melalui pretest, penilaian proses, postest, portofolio maupun penugasan terstruktur dan tugas mandiri tidak terstruktur sesuai dengan rencana penilaian, namun tujuan pembelajaran sudah tercapai, hal ini bisa dibuktikan dengan 12 (dua belas) mata pelajaran yang diajarkan di kelas IX, terdapat 8 (delapan) mata pelajaran yang siswanya tuntas semua sesuai dengan KKM yang sudah ditetapkan, dan hanya 4 (empat) mata pelajaran yang sebagian kecil siswa belum tuntas berdasarkan KKM, namun sekolah perlu secara bertahap meningkatkan KKM menuju KKM nasional.

\section{Saran}

1. Kepala Sekolah hendaknya: a) mengadakan kegiatan In House Training (IHT) dengan menghadirkan narasumber dengan materi pemanfaatan sumber/media pembelajaran. b) mengintensifkan kegiatan supervisi akademik untuk memastikan guru meningkat kompetensinya dalam pemanfaatan sumber belajar/media pembelajaran. dan penilaian proses dan hasil belajar. c) menambah alat peraga/media pembelajaran yang dibutuhkan oleh guru sehingga kualitas pembelajaran guru semakin baik, d) mengadakan kegiatan IHT/Workshop tentang penyusunan butir soal dan alat evaluasi agar kompetensi guru khususnya dalam penilaian proses dan hasil belajar dapat lebih berkualitas, e) mengadakan pemberdayaan kegiatan MGMP sekolah.

2. Guru hendaknya: a) aktif belajar mandiri dari berbagai sumber dan aktif mengikuti kegiatan IHT/Workshop, serta diklat yang diselenggarakan oleh LPMP dll tentang pemilihan dan pemanfaatan sumber/media pembelajaran, b) meningkatkan kompetensinya dalam komponen penggunaan/pe-manfaatan sumber belajar/media pembelajaran, dengan secara terbuka meminta kepala sekolah untuk mensupervisi pembelajaran dan memberikan masukan, c) meningkatkan kompetensinya dalam penilaian proses dan hasil belajar sehingga kualitas pembelajaran menjadi lebih baik, dengan cara aktif belajar mandiri dari berbagai sumber serta mengikuti kegiatan IHT/Workshop terkaitan dengan penilaian proses dan hasil belajar, d) mengembangkan kreativitas dan inovasinya dalam proses pembelajaran dengan mengembangkan/menciptakan alat peraga/ media pembelajaran serta memanfaatkan lingkungan sekolah sebagai sumber belajar, 
e) memiliki motivasi dan merasa tertantang untuk meningkatkan KKM mata pelajaran menuju KKM Nasional.

\section{DAFTAR PUSTAKA}

Arifin, Irvin Novita. 2007. Penerapan Model Pakem Dalam Meningkatkan Mutu Pembelajaran Gaya Gesekan Pada Siswa Kelas V SD Laboratorium Universitas Negeri Gorontalo. Jurnal Penabur UNG. Vol. 09, No. 2.

Arikunto, Suharsimi. 2008. Evaluasi Program Pendidikan. Jakarta: Bumi Aksara.

Asmani, Jamal Ma'mur. 2013. 7 Tips Aplikasi PAKEM. Yogyakarta: Diva Press.

Blimpo dan Evans. 2011. School-Based Management and Educational Outcomes: Lessons from a Randomized Field Experiment. SIEPR, Stanford University The World Bank. Nop. Vol. 4 No. 45.

Depdiknas. 2001. Manajemen Peningkatan Mutu Berbasis Sekolah. Buku 2: Panduan Penyusunan dan Pelaporan. Jakarta: Depdiknas, Ditjen Dikdasmen Direktorat SLTP.

Kafit, M. 2009. Efektifitas Media Pembelajaran Komputer UntukMeningkatkan Hasil Belajar Mata Pelajaran IPA Klas VIII MTs NU Hasyim Asyari 03 Honggowongso Jekulo Kabupaten Kudus. Semarang: Walisongo Press.

Mulyasa, E. 2014. Manajemen Berbasis Sekolah. Bandung: Rosda Karya.
Peraturan Pemerintah Republik Indonesia No. 19 Tahun 2005 Tentang Standar Nasional Pendidikan.

Ratam. 2009. Pengaruh Pola Pembelajaran Aktif, Kreatif dan Menyenangkan (PAKEM) dan Motivasi Belajar terhadap Ketuntasan IPS Materi Sejarah Siswa Sekolah Dasar di Kecamatan Karanganyar Kabupaten Purbalingga. Yogyakarta: UIN Sunan Kalijaga Press.

Rusman. 2010. Model-model Pembelajaran. Bandung: Mulia MandiriPress.

Slameto. 2009. Manajemen Pendidikan. Salatiga: Widya Sari Press.

Syaikhudin, Ahmad. 2008. Evaluasi Pelaksanaan Model Pembelajaran Aktif, Kreatif, Efektif, dan Menyenang-kan (PAKEM) di Madrasah Ibtidaiyah Negeri (MIN) Jejeran Bantul Yogyakarta. Yogyakarta: UIN Sunan Kalijaga Press.

Tri Wahyuningsih. 2010. Implementasi MBS dalam Upaya Peningkatan Mutu Sekolah di SMPN 1 Purwokerto Tahun ajaran 2010/2011. Tesis. Purwokerto: UNPPress.

Uno, Hamzah.2013. Belajar dengan Pendekatan PAIKEM. Jakarta: Bumi Aksara.

Usman, Uzer. 2008. Menjadi Guru Profesional. Bandung: PTRemaja Rosdakarya. 